\title{
"Plan for the Worst, Hope for the Best, but Realistically, Expect a Combination of Both: "Lessons and Best Practices Emerging from Community-Engaged Teaching During a Health Crisis
}

\author{
Angie Mejia, Ph.D. ${ }^{1}$ \\ ${ }^{1}$ Assistant Professor and Civic Engagement Scholar, Center for Learning Innovation, University of \\ Minnesota Rochester, USA
}

This is the submitted version of an article forthcoming in a special issue of the Journal of Higher Education Outreach and Engagement on community-engaged teaching and learning during the COVID-19 pandemic. Questions should be directed to the corresponding author, Angie Mejia, via email at amejiame@r.umn.edu

Suggested citation:

Mejia, A. "Plan for the Worst, Hope for the Best, but Realistically, Expect a Combination of Both:" Lessons and Best Practices Emerging from Community-engaged Teaching During a Health Crisis. Journal of Higher Education Outreach \& Engagement. [Forthcoming] 


\title{
"Plan for the Worst, Hope for the Best, but Realistically, Expect a Combination of Both": Lessons and Best Practices Emerging From Community-Engaged Teaching During a Health Crisis
}

\begin{abstract}
This article outlines a framework that I implemented when delivering a community-engaged course during the earlier days of COVID-19. I argue that these guiding principles-centering the community partners' needs, assessing and remaining flexible to students' circumstances, and cautiously mapping and selectively using institutional resources to deliver the course-allowed me to provide a community-engaged experience to undergraduate students despite pandemic restrictions. At the same time, I ensured that the intersectional feminist and critical ethos of the class was not compromised and that the commitment to the community partners' sustainability was not cast aside. Additionally, I share two detailed exemplars of community-based learning projects highlighting the possibilities, challenges, and limitations when applying this framework. I close this piece with several points of departure to stimulate future conversation among educators, researchers, and practitioners on the role of community-based service-learning during times of societal crisis.
\end{abstract}

Keywords: Critical community-engaged learning, centering the partnerships, student-centered, pandemic teaching

This article's title was inspired by a phrase I used as a sign-off for emails to colleagues teaching community-engaged classes like the one I teach. These emails, housed on a subfolder aptly named "Pandemic Teaching," were answered at a particularly unproductive and uncreative time of the workweek. We, the privileged few with time to organize our files, might also have had the time to answer such crisis emails from other colleagues teaching community-engaged courses. "What do you think of . . . ?" "So, when the IRB took too long to respond, what did you . ..." "My dean wants to know if my class ..." "My students are ghosting me . .." "I'm losing my mind trying to figure out how the students will complete..." "My community agency partnership has not responded since the stay-at-home order."

Like me, my colleagues expressed frustration about the lack of direction and support amid what appeared to be a sizable number of resources from our institutions and organizational bodies dedicated to supporting community-engaged pedagogy (broadly defined to include out-of-class community activities encompassing servicelearning advocacy and social justice offerings). I took this a step further and decided to write a venting letter to myself. First, airing out frustrations was my way to cope; later, it became a way to connect with others in a similar situation. I eventually toned down the letter and published it as an article titled "Community-Engaged Learning in Times of COVID-19, or, Why I'm Not Prepared to Transition My Class Into an Online Environment" (Mejia, 2020). These emails and conversations with readers of the earlier 
article inspired me to document how I restructured a community-engaged course, which is intentional in its intersectional feminist pedagogy and antioppressive praxis, in response to pandemic difficulties.

The following sections outline practices and lessons learned via two exemplars implemented to restructure a community-based learning undergraduate course at the University of Minnesota Rochester (UMR), a health and medical sciences campus, in response to the COVID-19 stay-at-home mandate. In addition to the support of faculty and staff, I owe my ability to deliver a class that supported 10 community-partnered projects and over 50 students to following three guiding and connected principles: centering, assessing, and mapping. At the start of the pandemic, our immediate response as instructors was to center the needs of our community partners and the community members they serve —what Grenier et al. (2020) referred to as "anchoring the partnership" (p. 4) -instead of finding ways to meet the learning objectives of the class. This act of anchoring the community partnerships was followed by coordinated and persistent efforts to assess and remain attuned closely to our students' needs during the first weeks of the pandemic. Finally, these first two elements meant having to map and selectively and strategically choose which existing institutional resources were needed to support the delivery of a community-engaged course while simultaneously creatively using the supports and strategies of noninstitutional sources. These approaches went against what I felt was higher education's need to "meet learning objectives" of our community-based learning initiatives without regard to the partners and organizational bodies facilitating this experience. Reflecting on this framework and the two exemplars that follow it shows the possibilities, challenges, and limitations of offering critical community-engaged courses in light of COVID-19 and similar sociopolitical crises.

Challenges were encountered when delivering this course and supporting community-based projects that comprised the bulk of the partnership connected to a small campus within a more extensive university system. COVID-19 made the adverse effects of higher education's institutionalization of community-engaged learning more visible. Showing the cracks made it much easier to create workarounds and deliver my class without compromising its intersectional feminist praxis. My campus and the state university system it belongs to, like many of those U.S. institutions of higher education that engage in service to the community, was and continues to operate under the influence of what Verjee (2010) called the "status-quo paradigm," a model in which "students . . . help people 'in need,' and 'do for the community' while enhancing their own learning, with an emphasis on the student as 'server' and community recipient as 'served"' (p. 7). Practices under this paradigm are not only responsible for causing "a drain on community agencies' limited resources" (Blouin \& Perry, 2009, p. 127) in that the labor of community partnerships tends to benefit students and the university more than the members they serve. More often than not, they cause further harm and solidify the inequities they seek to address. Faculty and other groups engaged in communitybased learning offerings that are antioppressive, social-justice-based, and critically transformative are forced to navigate against institutional constraints to nurture and maintain relationships with communities that are not based on asymmetrical power dynamics. 
After introducing the campus, my course's learning objectives, and communitybased research projects connected to my class, I expand on how the above-noted framework guided my revision and delivery of a connected set of practices that educators could replicate in a similar moment of crisis. The Exemplars section focuses on exemplars of two community-engaged activities that I developed for my students during the pandemic, one of which worked well and, at the time of writing, continues to operate as described. Another may have initially appeared to work but, despite the efforts, does not appear to be sustainable. Following the Exemplars section, I engage in a reflective detour geared to BIPOC (Black, Indigenous, and people of color) scholars working on community-engaged learning initiatives before closing with some thoughts on how academics, practitioners, and advocates can move forward with communityengaged learning efforts that uplift as well as empower communities.

\section{Context}

UMR is the smallest of a group of campuses that make up the University of Minnesota public university system. Serving around 600 students, UMR is known for providing a curriculum focused on the health and medical sciences, its connection to the Mayo Clinic, and faculty members' approach to innovative pedagogies. As an assistant professor of community engagement, I am responsible for developing, advising others on, and delivering community-based service-learning courses that pair groups of students with community partners implementing projects that range from direct-service engagement on site to research conducted on behalf of a community agency.

This text focuses on lessons learned from the rapid pandemic restructuring of one of these courses, Community Collaborative, geared to undergraduates. Community Collaborative is intentional in its intersectional feminist and critical approach to community engagement. It challenges students to critically engage with individuals and groups to understand, map out, and target unjust conditions that have disallowed communities from sustaining healthy and just futures. The critical feminist pedagogical moves (Costa \& Leong, 2012; Diaz, 2016; Solorzano \& Yosso, 2001) that I have integrated into the curriculum include citational practices that center material authored by women of color scholars (around $80 \%$ ) and three full sessions dedicated to intersectional theory (Crenshaw, 1991) and intersectional analysis (Collins, 2002) as they pertain to issues students are encountering in the community.

The class is delivered with six other instructors who guide groups of five to eight students, coordinate community projects, assess student progress throughout the semester, and liaise directly with community partner representatives. Community partners often meet with us to see how students can help deliver projects or engage in activities that meet their clients' needs. Community partners also assess student progress by supervising on-site activities and evaluating final presentations; their total contribution nets around $20 \%$ of the final grade. At one time, the course partnered with 11 agencies and had seven faculty members in charge of a total of 50 students. In fall 2020, we had seven projects, five faculty members, and 40 students. In spring 2021, we have 50 students supporting five community partners and two in-house projects. The class is also offered during the summer, with fewer students supporting one to two partners. 


\section{Three Steps to Pandemic Teaching}

As Flores et al. (2020) reflected on their transitioning of a community-immersed class during the earlier days of the pandemic, "Abandoning ... partners at the onset of a public health emergency would have been antithetical to the core values promulgated by the course" (p. 47). My experience and insights from many conversations with educators and practitioners delivering community-engaged learning indicate that the resources and strategies made available via our universities and institutional bodies that support experiential, service-learning, and other community-based learning revolved around that transactional paradigm of the university student as someone who expects that this opportunity serving the community should meet their needs as an educational consumer. Being asked to focus on the learning outcomes of a class without community centering, and in doing so, leaving community needs as an afterthought, not only shows how we are being asked to abandon our partners in a time of crisis but also how we had to pressure them to come up with ways to help us deliver this experiential aspect of our class. Thus, the three guiding principles (and the exemplars) outlined in the following sections should be taken as one way some faculty and practitioners might respond and resist the neoliberalization (Clifford, 2017) of campus-community-based learning.

\section{Center the Partnership and the Communities Partners Serve}

Lessons learned from health education service-learning practices (Flores et al., 2020) and community-engaged research (Wieland et al., 2020) during COVID-19 suggest that immediate and continuous response to partnership needs-avoiding delays and waiting periods to initiate partner contact-might prevent disparities in communities and ensure commitment to the partnership. This response is vital, as organizations might view community-campus learning initiatives as "an imposition and insensitive to community needs" (Verjee, 2010, p. 8). In addition, meeting "the short and longer-term needs of the host community should be the first and most important consideration" (Beaman \& Davidson, 2020, p. 3607) when seeking to deliver a community-engaged curriculum during times of rapid change. Thus, my initial energies went toward a rapid assessment of where my partners were at and how I could be of assistance, even if my help meant asking students to cease any off-site project-based tasks, such as telephone surveys, or if it meant getting my students and myself out of the community partners' hair altogether. Flores et al.'s (2020) recollections of teaching a community-engaged course highlighted how faculty members' ability to "freely verbalize ... mutual feelings of uncertainty and vulnerability about current events" ( $p$. 48 ) with community partners showed the strength of ongoing relationships founded on reciprocity and mutual respect.

My ability to quickly assess community partners' needs was aided by the strength of the relationships forged between them and the past and current instructors teaching this course. Thus, most of the partnering organizations were not shy about saying that my students and I would be more of a burden than a boon. In sum, my emails and calls to each partner were more along the lines of asking what I could do, not as a faculty member with students that needed something to do, but as someone connected to a university system with different forms of intellectual and organizational capital. During these conversations with partners, I quickly learned whether they were going on furlough status - temporarily ceasing on-site operations-ceasing operations altogether, 
or shifting agency operations to answer critical needs arising from COVID-19. One of our campus's partners, a social service agency serving older adults, had to move from its usual operations like a senior health fair, social outings, and hosting bingo nights to emergency-based services, including delivery of groceries for homebound seniors and similar immediate needs. After contacting each partner, often with assistance from coinstructors, I understood what to do with each of the students' groups in light of experiential activities.

\section{Assess Students' Needs}

As Veyvoda and Van Cleave (2020) indicated, "the most pressing concerns related to teaching and learning during the pandemic involv[e] basic needs" (p. 1544) of students as well as of staff. Knowing that some students had a few weeks to move out of student housing and try to take care of other needs beyond academics, I was honest with my partners about some not being able to continue working with their agencies. However, knowing that many of my students do entry-level healthcare work or are in health-related internships, I also informed the partner that those staying and still willing to do community work would need to coordinate changing schedules. The students would also face increased hours at their respective workplaces, making it more challenging to complete the partner's assigned duties and project tasks. I also was upfront about the risks involved if we could get the necessary permissions from my university to maintain students working on-site. Since our undergraduates are being trained as healthcare professionals, they understand the ins and outs of disease transmission. However, their employment situations as healthcare workers would still make them more susceptible to contracting COVID-19.

The pandemic's effect on students' lives should be immediately addressed by instructors and integrated into the curriculum. Flores et al. (2020), for example, related course concepts like social determinants of health to students' current difficulties as well as emphasizing "how these same issues may be manifesting for the most vulnerable members in their home communities" (p. 49). Other educators see the incorporation of COVID-19 on reflective exercises and assignments as a pedagogical move that helps students create new links to the material while addressing their well-being during rapid change (Christian et al., 2020). Part of taking the pulse of students' needs was to have conversations about how the pandemic affected their academic lives. Some of these conversations were conducted with an eye to what was needed for graduation for those nearing it. Is a grade in a non-STEM (science, technology, engineering, and mathematics) course like this one necessary for your postbaccalaureate goals, or could a pass/no pass substitution suffice? If this class was a way to gain professional experience, for example, would a withdrawal grade satisfy if the students continued working with the partner as a volunteer?

My coinstructors and I also became acutely aware of the students' material and emotional needs as they navigated this transition. A small percentage, especially those with complicated home lives, might have been going back to an unsafe place, which could remove them from the right "headspace" for engaging with the community partner. Besides, even in emotionally safe environments, students' new living situations may make it difficult for them to complete some service-learning tasks. Students with, say, spotty internet service, would not be able to perform some of the engagement tasks 
required by the partner. For those collecting data, living with family members may hamper their ability to conduct interviews and surveys with assured participant confidentiality. Taking technological issues into account, I also knew that the rapid shift to heavy dependence on learning management systems (LMS) for classes might further disadvantage those likely to struggle in an online learning environment.

Finally, the pandemic has affected students' overall engagement with my class's partnered projects as of writing this article. Centering the partnership's needs may have the unintended consequence of removing students from projects needed to meet various academic requirements, such as on-site research experiences, or programs that they found engaging, meaningful, or relevant to their future professional trajectories. Some of the community-partnered projects in my fall 2020 classes had to shift once again because of organizational changes related to COVID-19 issues.

\section{Cautiously Strategize the Use of Institutional Resources}

Talmage et al. (2020) suggested that rapid changes to community-engaged learning projects need not rely on resources outside the campus or focus on largescale, nonlocal alternatives to be successful. My initial scramble highlighted how the resources and strategies curated by regional and national higher education associations and service-learning networks would not assist me in anchoring the partnership or staying in line with the critical frameworks and antioppressive praxis during the rapid pivot of a community-engaged course.

Maybe I was naïve, but I felt slight irritation when I realized that my faculty partners and I, at least on our campus, were the only ones actively trying to find ways to assist struggling community partners during the earlier weeks of the pandemic. Administration and staff might have been too busy, as my emails came back with only vague statements of support. And from my vantage point, the office and staff that administers community-engaged and experiential learning at the systemwide university level were likely already overwhelmed by faculty requests from other campuses needing resources to shift to online-based service-learning courses. Without denying that these institutional supports might have been helpful to some, I found that finding ways to "keep teaching" and meeting the learning objectives without practical and actionable solutions or readily available resources to help our community partners felt one-sided. Besides, it felt antithetical to the maintenance of reciprocal and transformative relationships between community and campus and the intersectional feminist foundations of my curriculum.

After a day spent in utter frustration, I sought ways to maintain my class's critical stance by creatively using resources from the margins: for example, tapping into my activist networks for ideas and plans to deliver portions of my class online; changing some of the reading materials to more manageable formats such as blogs, podcasts, or social media focusing on COVID-19; and centering the needs of the partners while strategizing ways to use some institutional resources that were not directly connected to my course's learning outcomes. Below, I sketch out some of these strategically cautious uses of institutional resources to show how instructors might provide a communityengaged class without decentering the community partner's needs or failing to meet learning objectives. 


\section{Help From Displaced Staff Members Within the University}

I was lucky that my class is structured to be a collaborative endeavor. Each group of students has an individual faculty advisor to oversee the work and coordinate projects for one of the 10 community partners. This support gave me a bit of a breather, as I was able to assess all of my community partners' organizational capacities and willingness to continue to support students. At the same time, faculty advisors could meet individually with students to learn about their specific situations. If I had been without their support, I would most likely have turned to my university's systemwide Talent Share program. It temporarily matches staff members across the university who are experiencing a decrease in workload due to the pandemic with other divisions and campuses experiencing increased workloads for the same reason. Supporting and overseeing my students as they conducted online-based tasks for a partner, for instance, would have been very well supported by other staff members-even other undergraduates-displaced from their usual duties. Uprooted graduate students, for example, could have used their library skills to supervise student groups helping partners applying for emergency grants. Laboratory staff could have been able to help with logistical support of ongoing projects.

\section{Tapping Into COVID-19-Specific Responses by the University}

Are there COVID-19-specific responses that could be leveraged to anchor the partnership or meet students' needs? The 2nd week of the pandemic, I was connected to the university system's U-CAN COVID-19 network, a self-described collective of faculty, staff, and students tasked with figuring out how to support state, regional, and citywide efforts around the pandemic. Although the resources provided by U-CAN would not have helped me determine how to deliver the community-engaged portion of my course, they answered my community partners' immediate needs for volunteers with specialized skills such as grant writing and emergency fundraising. For example, the group connected one of my partners, a community garden serving refugee and minority growers, with two doctoral candidates to coordinate a long-term strategy for the increase of people seeking community garden plots during the crisis. The network also offered to connect another of my partners with volunteers well experienced in coordinating fast turnaround/large-scale emergency fundraising initiatives of in-kind and monetary donations. Organizing an appeal of that scope was outside my and my faculty partners' experience; my students would not have been able to undertake it without the direction of someone with specialized skills and training.

\section{Seeking In-House Projects}

Most of the community partners could not continue the project at all, either because they furloughed all of their staff or did not have the organizational capacity to support student engagement at a distance. Are there colleagues, departments, units, groups, and the like doing work that aligns with your community-engaged class's intellectual and political foundations? The Mapping Prejudice project, a digital humanities program at one of the campuses within my university's system, would have been on my list of possible in-house partners. This program uses crowdsourced volunteers to transcribe restrictive racial housing property covenants in Minneapolis and 
could have provided my students with the type of community-engaged learning opportunity that met the objectives of my course while online.

\section{Exemplars}

Considering the way my class was set up, the context, the levels of support, and the time available, I offer two vignettes showing both successful and not-so-successful outcomes of using this framework to substitute the original community work. These exemplars apply not only to project substitutions that occurred at the start of the pandemic but also current-as of writing this article-insights from my coteaching colleagues and reflections from the students. Centering the partnership, assessing students' needs, and cautiously mapping institutional resources, in some cases, might allow community-engaged learning initiatives to remain useful, meaningful, and relevant to the communities, students, and faculty/staff involved.

\section{"Using the Telephone Is Going to Make Me Anxious"}

One group of students assigned to a social service agency was originally scheduled to conduct individual weekly companionship visits with homebound older adults. They also planned to help with social group activities (such as game nights, community breakfasts, and student-led beauty and wellness spa days) for seniors who visited the agency's day site. Our university's request to cease all experiential learning activities (or substitute them with virtual tasks) placed this agency in a difficult position. Their older clients' health could be compromised if student visits continued, but stopping could leave an already socially disconnected group vulnerable to further isolation. After discussing it via email, the community partner asked that the students move to telephone conversations (twice a week for at least an hour) to retain relationships with their matches. Although the agency's clients had no problem with the calls, students were anxious about the change. Students feared that this would not have the same impact as face-to-face encounters, and the rapport they had established would suffer. Their anxieties were messaged to me via private Zoom chat, expressing that members of their generation "tend not to answer when cell phones ring" and hoping they did not "mess up the relationship" they had built with their older adult match. After the faculty member overseeing this group and I met with each student to understand their needs due to the pandemic, we felt (even if they initially disagreed) that they were ready to begin phone calls. Three weeks into the distanced visits and agency-directed tasks, most students reported that relationships with their matches remained as strong as before and did not show signs of losing interest or becoming disengaged.

In addition, their reflective journals suggested a sense of shared purpose brought on by a global health crisis. Since the agency had once requested help designing a more community-based project to further incorporate their clients' voices, students began consulting with a colleague who performs archival research. They started to plan for next semester's class to conduct oral history interviews with the older adults. Despite the project's shift to online, students agreed that the course's meaningfulness was retained and that preparing the oral history proposal further enriched their learning. As of now, any student activities connected to this agency (which involve telephone conversations with seniors and research-based tasks) will continue to adhere to social distancing protocols for the protection of the immunosuppressed clientele. Furthermore, 
the groundwork has been laid so that future students can conduct the oral history interviews the agency has wanted. Tentatively titled Past as Praxis, the project will frame older adults' recollections around previous public health crises as lessons for medical providers envisioning better healthcare futures in light of present uncertainties.

Interestingly, none of the resources that I sought could help me deliver the community-engaged portion that met the social needs of vulnerable individuals in the way that the partner wanted. I found lists upon lists of e-volunteering sites providing some form of Zoom-based contact with nonlocal members. Other suggestions included crowdsourced volunteering opportunities or having the students engage in the partner's back-burner projects, such as creating websites, brochures, or informational binders. Running around looking for busywork would have made more chores for us and brought a dynamic that disengaged the students. For example, how do I track and assess student work on an e-volunteering project? What do I know about their technical skills or their new living situations? And how do the students feel about being pulled away?

The success of this partnered project rested on centering the partners' needs while working with the students to understand if they could continue with their adult matches under shifting circumstances (some had moved back home and found themselves with additional responsibilities) and with different technological set-ups (many faced internet connectivity issues, but cell phone access was a given). The reworked activities remained relevant to the course objectives and written work. I also kept myself from asking to integrate students into emergency volunteer needs: Even with a volunteer coordinator working full time, the agency might not be ready to train them. My faculty colleague and I worked with the partner separately, providing other forms of support (such as finding specialized volunteers, emergency sources of donations, or university-based resources) to assist them with their work.

\section{"Just Get Them to Zoom and [Snaps Fingers] Done"}

Some colleagues indicated that their universities provided ideas and resources to shift face-to-face service-learning activities into online ones. The literature suggests that institutional resources have been creatively leveraged to assist community partnerships. For example, institutions have allowed community partners to tap into technological resources (Opara et al., 2020), such as institutional Zoom accounts with extended session times and other benefits. However, I did not learn about this prospect until months into the pandemic, and my university's communication and approval processes would have been too difficult to navigate for some of my community partners. Even if I had known about this earlier, it would have taken too long to set up and implement. Inkind institutional responses and resources are helpful only if needed to conduct all of the partner's operational needs and not just the work connected to the service-learning.

Even though some of my partners may have had the set-up to connect with their clients online (and, in some cases, clients could be connected using iPads provided by their public schools as they shifted to online learning), "just use Zoom" was not as successful even with several contingencies in place. Out of the six partnerships with the ability to facilitate Zoom access for students to engage in some form of service-learning activity, only two of them did. Only one has continued coordinating Zoom-facilitated direct service efforts with members of the communities they serve. 
One of my partners, an after-school youth organization, did not want to "overpromise and underdeliver" an experience with their clients. They indicated that, although my students' backgrounds in health sciences and STEM would have helped pre-COVID tutoring set-ups, many of their clients were not Zooming in to their eactivities. This partner felt that many of their clients were not attending because parents, already overworked trying to homeschool, may not have had the capacity to coordinate and oversee their children logging in. One of the coordinators, who had conducted telephone calls with the parents and guardians who had taken part in the socially distanced activities during the summer, shared these clients' feelings of stress that too many people were seeing "their messy homes" and lamenting a loss of privacy.

After a long conversation in which a director of an established nonprofit kept on expressing relief that I was not pressuring them to keep my students "doing some busywork or other," they became even more candid about their views on technology. They shared that "there is no manual, no training, no website" on how to manage volunteers over Zoom. They also expressed worries about how video chatting prevents people (both volunteers and coordinators) from reading those important facial and bodily cues while working face-to-face. Further, they indicated that those other ways of communicating with coworkers and trainees could not be transferred into the Zoom environment. They also learned that their communities had little interest in attending online versions of pre-COVID services and activities.

In addition to these issues, there have been unexpected problems in two of the service-learning opportunities, even with the capacity, technological support, and dedication of both agency staff and learners to make it work. For one of the partnered projects, which set students to engage in direct service activities with multicultural families and youth via various organizations, connecting online has not been a smooth ride. In this quote, one of the students speaks to the difficulty of providing tutoring via Zoom, even when she chose this engagement project because she likes teaching and often tutors sophomores at our campus: "Subjects like Math and English can be especially challenging because [young students use] worksheets and printed packets and it can be hard to see the papers through the cameras."

Another student, supported by both staff at my campus and a dedicated coordinator paid by a multiagency initiative to help deliver tutoring online, reflected on the difficulties of getting through one session:

There is still the issue that it is sometimes hard to tutor students over video chat because students and tutors are still trying to get used to the format of the teaching sessions. It is also difficult because sometimes parents don't know how to use the technology to help students access the tutoring session. With the first two weeks of tutoring, some of my students struggled to log on to [the session], so [the agency's coordinator] and [the IT department support staff at the campus] changed the session to only include one Zoom meeting for everyone to join, and then we go into breakout rooms.

The digital divide in underserved communities has been augmented by the pandemic (Seymour et al., 2020). In later reflections, my students became aware that 
the needs of many clients served by agencies providing educational support could only be met by systematic infrastructural changes (Kim \& Padilla, 2020). Families, especially non-White families, do not just require internet and access to technology; they also need the material, emotional, and political conditions in place to weather this pandemic at home.

Even with the difficulties, this group and other students indicated they were "getting used to it" and powering through their anxieties and Zoom fatigue from online classes, in order to deliver tutoring services. All of them, as well as those students working for other partners, showed us that, despite the difficulties, they were enthusiastically ready to do what they could to give the community the best experience possible. As one related, "What we ended up doing was having the kids hold up their assignment to the camera so we could read the questions and help them answer it."

This experience with online tutoring counters not only some of the carefully curated "delivering a community engagement course during COVID" lists of resources and advice made available to educators by many nonprofit organizational bodies but also, broadly speaking, the literature around online learning. I wrote more critically about the former's efforts in an earlier publication about teaching during a pandemic (Mejia, 2020). For the latter, however, those of us on the ground (and most likely writing on, speaking of, and sharing with others about our attempts to use these technologies) are noticing how much is missed and how much more there is to learn about these new pedagogical spaces and the practices we are forced to engage in at a time of societal change.

As of the date that this report was written, final analyses of this situation have been perceived as positive by several people. After a student presentation of how they, as tutors, learned about themselves and the structural challenges affecting their tutees, many people congratulated us. I was praised for the activity, as it was suggested that the experience allowed students to "really operationalize class concepts." The students, in turn, were congratulated for "doing an excellent job despite it all." In my responses, I have reframed how their engagement with the partner was difficult and complex, emphasized that the setting and context was not ideal for everyone involved, and stated that I feared, even if I anchored the partnership's wishes, that the educational gains of tutees might have been minimal, as there is no way to measure and assess impact. Additionally, spring 2021 students have noticed a sharp decline in attendance to Zoom tutoring meetings due to changing school schedules and, most likely, family members' fatigue of having to coordinate when their children can attend.

In this particular vignette, we can see how critical approaches like the one I advocate for-anchoring the partnership, dedicating more time, and providing additional support to students conducting online service-learning activities in the community while remaining openly critical of the conditioning that dictates how such activities ought to be conducted-can still risk community partnership relationships with higher education bodies remaining "transactional" (Stewart \& Alrutz, 2012) and never becoming transformative. In this particular case, constant communication with the agency means that I will make sure that they do not feel obligated to provide the experience if it is not going to be helpful to them. 


\title{
Operating at the Margins While Speaking From the Margins: Some Words Geared to Historically Marginalized Scholars Teaching During the Plague
}

\begin{abstract}
"The only thing that's good where you at is Prince. And he's dead."
My sister and I just argued about the person I am now that I live in the Midwest. The conversation was tense as I cannot travel to the Pacific Northwest, and she is unwilling to come here. "You're such a chipster," I said as I ended the call. A chipster, a portmanteau of hipster and Chicana, is what I have been using when referring to my younger sister because I was a bit envious of her. The White nonsense she needs to deal with where she lives in Portland is different from what I have to deal with in Minnesota. But all I want to tell her is that I am tired. I am anxious. I am also overwhelmed. And that I am, well, really, there are so many I am's that I must contend with lately. I am the only faculty member that has been specifically hired to design and direct community-based learning initiatives on my campus. I am one of the few women of color instructors, one of three, and the only one on the tenure track at the moment. I am also someone who embodies various sociopolitically devalued identities in a place where Whiteness has a unique way of affecting those who do not fit in. (Oh, so nicely!) And at the time of drafting this article, I am a faculty woman of color observing others on my campus and others that comprise the university system that cuts my check, coming to terms that Minnesota Nice ain't going to cut it this time.

Teaching on a campus located 80 miles from the site where a White police officer asphyxiated a Black man with his knee, at a time where science denialism is on the political menu, has made my labors and responsibilities to my family, my students, and those that get paid more than me, feel infinite. It has meant that I had to figure out how to deliver the learning objectives of my community-engaged class in a way that does not go against my training as an intersectional feminist and my values of being raised in family settings where social justice was a significant part of how the grown-ups in my life lived theirs. And I had to do it while the majority of those around me were undergoing some form of racial awakening. I am ... yes, I am navigating a pandemic spring and summer filled with the exhaustion of figuring out class schedules, community logistics, shifting reading timelines, and modified reflection assignments while also dealing with requests to talk, meet, discuss, facilitate, dialogue, and whatever other verbs I can add, from those who have now discovered that systemic racism is real and now want to talk to someone who is not White. And I am tired.
\end{abstract}

Faculty of color are more likely to be overrepresented in the design and delivery of community-based learning curriculum and coursework (Baez, 2000). I am a faculty member embodying various sociopolitically devalued identities, including a racializedgendered one. This meant that centering the needs of my community partner, remaining aware of the multiplicity of students' issues, and strategically implementing existing 
institutional and other resources to deliver my course, made me likely to engage in counternormative practices with possible negative reverberations. Below, I reflect on several of these counternormative choices as a way to share possible challenges that Black, Indigenous, and people of color (BIPOC) faculty teaching community-engaged courses may encounter when implementing some of the guiding principles I shared earlier in this article.

Removing readings, assignments, and activities and replacing them with others that conformed to my vision of Community Collaborative was already a risky move. As a great Italian American diva once described the relationship between moves and motion as "causing a commotion" (Madonna, 1987), my curricular choices appeared to be causing a commotion of sorts. (In light of Midwestern White people's sensitivities.) According to my ex-PhD advisor-now friend, my syllabus was "tame" compared to what she has seen me introduce in the past. "I thought you would be adding more," she said as she looked at my reading list. We had met for one last lunch rendezvous in the city before completing my move to Rochester, Minnesota. I reminded her this is a STEM campus, and my class is the everyone-has-to-take-it-to-graduate-often-said-with-agroan class. Later on, students of my spring 2020 semester had already learned from others that the class "was not as easy" as when so-and-so took it and that it had "too much reading." Seeing that service-learning and Whiteness (Bocci, 2015; Green, 2001; Mitchell et al., 2012) have an interesting history that I will not focus on in this text, I made several changes to the curriculum. I intentionally replaced all of the usual readings with works written by BIPOC scholars. Not only was creating a syllabus-withtoo-many-articles-to-read-for-STEM-students-in-a-place-where-a-smile-might-not-meana-smile my response to the "invisibility and normative privileges of Whiteness [that] shape . . . and are reinforced by service-learning" (Mitchell et al., 2012, p. 615), it was my way of practicing the citational justice praxis advocated by Sara Ahmed and other women of color. Causing a commotion, by Minnesota standards, and making sure more than $80 \%$ of the readings were from subaltern authors, was my way to "acknowledge our debt to those who came before; those who helped us find our way when the way was obscured because we deviated from the paths we were told to follow" (Ahmed, 2016, pp. 15-16).

In addition to the curriculum, the way that I would engage with new and existing community partnerships needed to embody a similar spirit of antioppressive theory and praxis. Six of the nine partnerships were headed by people who did not fit into the region's standard-five of them were led by BIPOC individuals. One of those agencies was led by a person who sat on my hiring committee. All of them knew where I stood and that I understood that they were not only providing our students with unique opportunities but that they were doing this knowing full well that the campus and the university system needed them more than the other way around. Three of the six coinstructors in this class were present during my job talk months before; one of them had a say on my hiring. Meaning, most people knew who and what they were getting into when they got me. And they could at least imagine how I would react to the institutional processes that shape how universities in the United States enter and attempt to maintain ties to the communities that help deliver community-engaged educational experiences. 
But the curriculum was the least of my worries here. Most students enrolled in fall 2019 were okay with it. Yes, the usual outlier reacted less than positively to exploring White supremacy in a reflection assignment or two. And the majority of students of color felt the class was one they wished they had taken earlier in their college trajectory. Whether it happens during a pandemic or in times of relative normality, centering the partnership and community needs appears to be more detrimental to the BIPOC scholar than choosing to deliver a curriculum based on subaltern knowledge. In my case, centering these needs meant that I was decentering the "musts" imposed on minoritized faculty who engage in community-based learning, teaching, and research by all of those who manage the institutionalization of community-campus initiatives. (Talk about causing a commotion.)

During the earlier days of COVID-19, most of my time and energy had to be devoted to my partners and the communities they serve, as well as my students. This situation also meant that an excess of labor for any existing service obligations, committees, and the like would push me to work on weekends. This impossible number of obligations during the pandemic has been the norm for women faculty (Dingel et al., 2021; Minello, 2020). It also meant that I would not enter into any new obligations connected to COVID-19 and campus-community desires to help, most of them coming from outside or from systemwide. I had no time. And, in much honesty, attending webinars about teaching during COVID-19, especially the ones geared to communityengaged teaching, ended up fueling my desire to write why these and other institutional resources were not helpful. Hence this article. The times that I did attend, I was forced to listen to 30 minutes of whoever repeating the same things that did nothing to help me or help my community partners and 15 minutes in Zoom breakout rooms to jot down ideas on what we were already doing. And unsurprisingly, those breakout rooms were a mix of people asking, "Does anyone have anything?" while another responds, "I came because I wanted to see where you were all at." And another attendee asking, "You?" After attending three of these webinars, I felt that my time could be spent elsewhere. And when George Floyd was murdered, there were more seminars with even more things that did not help me but did add to a persistent sense of emotional exhaustion.

The problem here was not the lack of resources, but that my absence, as one of two people engaged in community-based initiatives in my campus (the other one being our director of experiential learning), was hypervisible. At one point, I was sure that I would not be missed because the meetings, the workshops, and the talks were attended by so many people across campuses. However, I eventually learned that there was a noticeable absence when someone outside my campus cautioned that "not being present" could be detrimental in the near future. My decision to carve time and find ways to be present during these many system-level gatherings, including answering emails connected to whatever asks were attached to them, could also be a detriment to someone from the margins, operating from the margins, and attempting to stay in the margins. In a way, this was saying something to those that operate from the center. As I finish this reflective detour, I have yet to understand the implications of my absence, which would not be perceived negatively nor affect me in negative ways if I were a White faculty member.

I penned this section somewhat candidly as a way to highlight the possible implications of conducting community-engaged learning from the margins. In contrast to 
others, those who operate from the margins, or in ways that go against the usual practices, find themselves delivering an educational experience that does not engage the community as cocreators of knowledge and as instructional partners. If "positionality may determine the extent to which we can successfully implement" (Latta et al., 2018, p. 48) critical approaches to community-engaged teaching and learning, then how does it shape the spaces that we can operate from to transform them? Knowing that positionalities made vulnerable by axes of difference and power shape those spaces, places, and practices to imagine transformative ways of engaging in community with our communities, then how do moments of crisis figure into this dynamic? As can be deduced from this section, a pandemic, in addition to embodying intersectional differences in a place where such distinctions are highly noticeable, forced me to figure out how to deliver a community-engaged curriculum that stayed true to its intellectual and political, as well as educational, objectives while not decentering the community. However, it is yet to be seen what the afterlives of my decisions look like postpandemic.

\section{Discussion}

Service-learning activities pivoted due to COVID-19 have been shown to be successful when centering the community partnerships' needs (Flores et al., 2020; Talmage et al., 2020). Gresh et al.'s (2020) service-learning class geared to nursing students exemplified this approach. The authors attributed the success of their community-partnered course to focusing on the needs of the partner and their clientele while staying loyal to practices and processes of reciprocity, faculty engagement, critical written reflective work for students, creative use of existing resources, and remaining informed and inspired by a critical analysis of power. In this text, I outlined a model that advocates centering the needs of community partners with a prompt assessment of demands on their operational capacity due to COVID-19 while simultaneously and carefully shifting parts of the curriculum to match students' evolving needs and working from the margins via cautious/strategic use of institutional resources.

As noted by my exemplars and other published work on community-engaged learning during this crisis, there are certain limitations when choosing to center the partnership, remaining open and flexible to students' needs, and choosing to limit one's use of existing resources and strategies. There are stressors to the faculty and staff members delivering the curriculum online and preserving the critical praxis that shapes it. Student disengagement from the community-partnered projects might remain despite our efforts to be flexible. For many of us, the scramble to provide community-engaged courses left no time to implement assessment of student learning and community impact. Sociostructural issues, such as the unequal access to technology in historically disadvantaged and underserved communities, might affect projects that a community partner and the community itself had planned to deliver with student help and willingness, faculty guidance, and technological support. Finally, faculty and practitioners of community-engaged service-learning who are also members of minoritized groups might end up putting themselves against more mainstream approaches to campus-community-based learning, thereby further jeopardizing their professional futures.

The framework I outlined in this article was not only inspired by what others have noted to be the institutionalization and neoliberalization of community-engaged learning 
but was shaped by many community members' critiques of partnerships between themselves and the university as asymmetrical, unequal, and disempowering, a sentiment captured by Stoecker and Tryon's (2009) question, "Who is served by service-learning?" With this sentiment in mind, I end this piece on a few points of departure to explore community engagement learning, research, and practice in light of a postpandemic moment.

- Learning: What practices, if any, have worked in delivering a communityengaged educational online experience that does not create burdens for those it seeks to serve and transform? How have these rapid shifts to online delivery of community-engaged courses shifted students' attitudes toward community engagement?

- Research: How do we examine the way relationships between community groups and our respective universities operate? How do we measure, with an eye toward reparation and accountability, a campus's impact on communities? Seeing that COVID-19 has made visible these fractures and shown the inconsistencies between the ethos of a university in the service of the community and the reality of communitybased learning as institutionalized and shaped to meet neoliberal demands of the student as a consumer, how do we begin collecting and amplifying community members' narratives of the value of campuscommunity learning initiatives during COVID-19?

- Practice: How do we implement practices and assess community impact in ways that center community voices and empower stakeholders while keeping higher education accountable? Finally, and this comes from my conversations with many community partners along the lines of "you [the university in general, and faculty in particular] need us [community partners] more than we need you," how do we measure community resilience and transformation in the absence of reciprocal and transformative relationships with higher education and in response to the current transactional nature of these relationships?

\section{Conclusion}

My goal with this article was to share a set of guidelines, including best practices and those that are definitely not the best, for educators positioned to deliver communityengaged university-level coursework during times of societal crisis like a pandemic. The rapidly developed workarounds that make up this framework-centering the partnership, assessing students' needs, and cautiously and strategically implementing existing institutional resources-emerged from moments that I called "crisis teaching." Said moments have positioned many educators and practitioners like me to interrogate, collude with, and navigate institutional processes that counter the intellectual foundations of our courses and the community-based knowledge(s) and practices that strengthen the scholarship we cocreated with various communities that welcome us in the spirit of collective betterment.

Throughout this text, my tone urges others to critically examine how departments, campuses, organizational bodies, and coalitions working on behalf of 
higher education's community-campus initiatives may or may not be prepared to provide this support during disruptive social moments. Portending that those of us in higher education will once again experience rapid transition due to societal crises, I argue that the effects of this pandemic have made more visible, and possibly easier to shift and transform, critical concerns in how universities continue to engage with the communities they claim to serve. As others have demonstrated (Blouin \& Perry, 2009; Brackmann, 2015; Costa \& Leong, 2012; D’Arcangelis \& Sarathy, 2015; Stoecker \& Tryon, 2009), practices of a neoliberal university, which in part have capitalized on the service to the community element, are antithetical to reciprocity and reproduce community-campus connections, obligations, and responsibilities that are hierarchical and detrimental and, at times, exploitative. Knowing this, what should those of us who choose to teach, research, and practice community engagement in higher education take into consideration as we continue to perform this work? I say this knowing that many of us choose to remain on this path despite the detrimental effects on our professional lives. The pandemic has made it clear that many of us will not tolerate the way it has always been and are willing to imagine something better. Perhaps the work should be that of continuing to advocate for and establish the conditions that position communities to thrive while simultaneously challenging those that prevent them from doing so.

\section{References}

Ahmed, S. (2016). Living a feminist life. Duke University Press.

Baez, B. (2000). Race-related service and faculty of color: Conceptualizing critical agency in academe. Higher Education, 39(3), 363-391. https://doi.org/10.1023/A:1003972214943

Beaman, A., \& Davidson, P. M. (2020). Global service-learning and COVID-19-What the future might look like? Journal of Clinical Nursing, 29(19-20), 3607-3608. https://doi.org/10.1111/jocn.15369

Blouin, D. D., \& Perry, E. M. (2009). Whom does service learning really serve? Community-based organizations' perspectives on service learning. Teaching Sociology, 37(2), 120-135. https://doi.org/10.1177/0092055X0903700201

Bocci, M. (2015). Service-learning and White normativity: Racial representation in service-learning's historical narrative. Michigan Journal of Community Service Learning, 22(1), 5-17. http://hdl.handle.net/2027/spo.3239521.0022.101

Brackmann, S. M. (2015). Community engagement in a neoliberal paradigm. Journal of Higher Education Outreach and Engagement, 19(4), 115-146. https://openjournals.libs.uga.edu/jheoe/article/view/1235

Christian, D. D., McCarty, D. L., \& Brown, C. L. (2020). Experiential education during the COVID-19 pandemic: A reflective process. Journal of Constructivist Psychology. https://doi.org/10.1080/10720537.2020.1813666

Clifford, J. (2017). Talking about service-learning: Product or process? Reciprocity or solidarity? Journal of Higher Education Outreach and Engagement, 21(4), 1-13. https://openjournals.libs.uga.edu/jheoe/article/view/1357

Collins, P. H. (2002). Black feminist thought: Knowledge, consciousness, and the politics of empowerment. Routledge. 
Costa, L. M., \& Leong, K. J. (2012). Introduction: Critical community engagement: Feminist pedagogy meets civic engagement. Feminist Teacher, 22(3), 171-180. https://doi.org/10.5406/femteacher.22.3.0171

Crenshaw, K. (1991). Mapping the margins: Intersectionality, identity politics, and violence against women of color. Stanford Law Review, 43(6), 1241-1299. https://doi.org/10.2307/1229039

D’Arcangelis, G., \& Sarathy, B. (2015). Enacting environmental justice through the undergraduate classroom: The transformative potential of community engaged partnerships. Journal of Community Engagement and Scholarship, 8(2), Article 10. https://digitalcommons.northgeorgia.edu/jces/vol8/iss2/10

Diaz, S. P. (2016). A map for feminist solidarity: How to teach about women of color and reproductive justice in Jesuit WGS classrooms. Feminist Teacher, 27(1), 24-46. https://doi.org/10.5406/femteacher.27.1.0024

Dingel, M., Nichols, M., Mejia, A., \& Osiecki, K. (2021). Service, self-care, and sacrifice: A qualitative exploration of the pandemic university as a greedy institution. The ADVANCE Journal, 2(3). https://doi.org/10.5399/osu/ADVJRNL.2.3.2

Flores, D. D., Bocage, C., Devlin, S., Miller, M., Savarino, A., \& Lipman, T. H. (2020). When community immersion becomes distance learning: Lessons learned from a disrupted semester. Pedagogy in Health Promotion, 7(1), 46-50. https://doi.org/10.1177/2373379920963596

Green, A. E. (2001). "But you aren't White": Racial perceptions and service-learning. Michigan Journal of Community Service Learning, 8(1), 18-26. http://hdl.handle.net/2027/spo.3239521.0008.102

Grenier, L., Robinson, E., \& Harkins, D. A. (2020). Service-learning in the COVID19 era: Learning in the midst of crisis. Pedagogy and the Human Sciences, 7(1), Article 5. https://scholarworks.merrimack.edu/phs/vol7/iss $1 / 5$

Gresh, A., LaFave, S., Thamilselvan, V., Batchelder, A., Mermer, J., Jacques, K., Greensfelder, A., Buckley, M., Cohen, Z., Coy, A., \& Warren, N. (2020). Service learning in public health nursing education: How COVID-19 accelerated community-academic partnership. Public Health Nursing, 38(2), 248-257. https://doi.org/10.1111/phn.12796

Kim, C. J. H., \& Padilla, A. M. (2020). Technology for educational purposes among lowincome Latino children living in a mobile park in Silicon Valley: A case study before and during COVID-19. Hispanic Journal of Behavioral Sciences, 42(4), 497-514. https://doi.org/10.1177/0739986320959764

Latta, M., Kruger, T. M., Payne, L., Weaver, L., \& VanSickle, J. L. (2018). Approaching critical service-learning: A model for reflection on positionality and possibility. Journal of Higher Education Outreach and Engagement, 22(2), 31-55. https://openjournals.libs.uga.edu/jheoe/article/view/1386

Madonna. (1987). Causing a commotion [Song]. On Who's that girl. Sire Records.

Mejia, A. (2020). Community-engaged learning in times of COVID-19, or, Why I'm not prepared to transition my class into an online environment. Public Philosophy Journal, 3(1). https://doi.org/10.25335/ppj.3.1-3

Minello, A. (2020, April 17). The pandemic and the female academic. Nature. https://doi.org/10.1038/d41586-020-01135-9 
Mitchell, T. D., Donahue, D. M., \& Young-Law, C. (2012). Service learning as a pedagogy of Whiteness. Equity \& Excellence in Education, 45(4), 612-629. https://doi.org/10.1080/10665684.2012.715534

Opara, I., Chandler, C. J., Alcena-Stiner, D. C., Nnawulezi, N. A., \& Kershaw, T. S. (2020). When pandemics call: Community-based research considerations for HIV scholars. AIDS and Behavior, 24(8), 2265-2267. https://doi.org/10.1007/s10461020-02878-2

Seymour, K., Skattebol, J., \& Pook, B. (2020). Compounding education disengagement: COVID-19 lockdown, the digital divide and wrap-around services. Journal of Children's Services, 15(4), 243-251. https://doi.org/10.1108/JCS-08-2020-0049

Solorzano, D. G., \& Yosso, T. J. (2001). Critical race and LatCrit theory and method: Counter-storytelling. International Journal of Qualitative Studies in Education, 14(4), 471-495. https://doi.org/10.1080/09518390110063365

Stewart, T., \& Alrutz, M. (2012). Meaningful relationships: Cruxes of universitycommunity partnerships for sustainable and happy engagement. Journal of Community Engagement and Scholarship, 5(1), Article 6. https://digitalcommons.northgeorgia.edu/jces/vol5/iss 1/6/

Stoecker, R., \& Tryon, E. (2009). Unheard voices: Community organizations and service learning. In R. Stoecker, E. A. Tryon, \& A. Hilgendorf (Eds.), The unheard voices: Community organizations and service learning (pp. 1-18). Temple University Press.

Talmage, C. A., Annear, C., Equinozzi, K., Flowers, K., Hammett, G., Jackson, A., Kingery, J. N., Lewis, R., Makker, K., Platt, A., Schneider, T., \& Turino, C. (2020). Rapid community innovation: A small urban liberal arts community response to COVID-19. International Journal of Community Well-Being. https://doi.org/10.1007/s42413-020-00074-7

Verjee, B. (2010). Service-learning: Charity-based or transformative. Transformative Dialogues: Teaching \& Learning Journal, 4(2), 1-13. https://journals.kpu.ca/index.php/td/article/view/1173

Veyvoda, M. A., \& Van Cleave, T. J. (2020). Re-imagining community-engaged learning: Service-learning in communication sciences and disorders courses during and after COVID-19. Perspectives of the ASHA Special Interest Groups, 5(6), 15421551. https://doi.org/10.1044/2020_PERSP-20-00146

Wieland, M. L., Doubeni, C. A., \& Sia, I. G. (2020). Community engagement with vulnerable populations. Mayo Clinic Procedures, 95(9), S60-S62. https://doi.org/10.1016/j.mayocp.2020.05.041 